\title{
Influence of the Radial Clearance of a Squeeze Film Damper on the Vibratory Behavior of a Single Spool Gas Turbine Designed for Unmanned Aerial Vehicle Applications
}

\author{
Geraldo Creci, ${ }^{1}$ José Orlando Balastrero, ${ }^{1}$ Sidney Domingues, ${ }^{1}$ \\ Luis Vanderlei Torres, ${ }^{2}$ and João Carlos Menezes ${ }^{3}$ \\ ${ }^{1}$ Instituto Federal de Educação, Ciência e Tecnologia de São Paulo, Av. Francisco Samuel Lucchesi Filho 770, \\ 12929-600 Bragança Paulista, SP, Brazil \\ ${ }^{2}$ Universidade Estadual de Campinas, Rua Mendeleyev 200, 13083-860 Campinas, SP, Brazil \\ ${ }^{3}$ Instituto Tecnológico de Aeronáutica, Pr. Marechal Eduardo Gomes 50, 12228-900 São José dos Campos, SP, Brazil
}

Correspondence should be addressed to Geraldo Creci; gcreci@ifsp.edu.br

Received 26 September 2016; Revised 10 January 2017; Accepted 22 January 2017; Published 19 February 2017

Academic Editor: Athanasios Chasalevris

Copyright (C) 2017 Geraldo Creci et al. This is an open access article distributed under the Creative Commons Attribution License, which permits unrestricted use, distribution, and reproduction in any medium, provided the original work is properly cited.

\begin{abstract}
This study presents a numerical investigation using the finite element method on the vibratory behavior of a single spool gas turbine designed for unmanned aerial vehicle applications. The shaft of the rotor-bearing system is supported on a front bearing composed of a deep groove ball bearing with a vibration absorber element and a rear squeeze film damper bearing. Three radial clearances for the squeeze film damper were analyzed to determine the best geometric configuration for the rear bearing, considering the rotordynamic performance of the entire system. Whirl speeds and unbalanced system responses were carefully evaluated to determine the best radial clearance for the squeeze film damper. After defining the best radial clearance, a transient analysis was performed to simulate the transition of the system through resonance, and a spectral map is presented to illustrate the vibratory behavior of the system considering the influence of all related important frequencies. The rotordynamic behavior of the system is predicted, and vibration problems are avoided. Its mechanical drawings were released to manufacturing, and the first prototype is in the experimental test phase, thus indicating that the numerical results presented in this study are consistent.
\end{abstract}

\section{Introduction}

The demand for more powerful rotating machines has led to higher operating speeds, which has resulted in the need for an accurate prediction of the dynamic behavior of rotating machines in the design and development stages to avoid undesired vibration conditions at operating speeds. Understanding the physics of rotating machines is essential in several application fields [1-4]. For example, the safety and service life of rotating machinery in aerospace, automotive, and power plants are directly linked to the high quality of their vibratory behavior. A high level of reliability, increased operation, and decreased unscheduled maintenance is becoming increasingly desirable for the currently developed industry products [5].
The rotors in rotating machines are always slightly unbalanced due to manufacturing and assembling inaccuracies. In the rotating components of turbine engines, particularly bladed discs, one of the primary sources of structural uncertainty is mistuning. Mistuning refers to variations in the characteristics of each sector of a system that is ideally expected to be cyclic symmetric [6-8]. It generally results in a slight variability in the dynamical responses and induces localization phenomena and stress magnification. In particular, if the critical speeds are exceeded, then the unbalance produces a vibration of large amplitude.

A full rotordynamic analysis is mandatory to avoid vibration resonance at operating speeds. Critical speeds are defined as coincidences in the shaft rotating speed and the rotating natural frequencies of the rotor-bearing system. 
Because catastrophic failure occurs at critical speeds due to resonance, critical speeds are designed to be sufficiently separate from the operating speed range. Furthermore, determining both the instability threshold and unbalanced system responses is of significant concern [9-11].

There are several numerical approximations for the vibration analysis of rotor-bearing systems. The most popular approach, which is particularly well-suited for modeling large scale and complicated systems, is the finite element method [12-17]. In recent years, several articles have been published addressing full dynamic analyses in numerous types of rotating machineries and have involved complete investigations of the rotordynamic behavior in the respective application and avoid vibration problems [18-30].

In this study, a full rotordynamic analysis is performed for a single spool gas turbine designed for unmanned aerial vehicle applications. The referred gas turbine has been developed as an academic research project in association with industry. It is important to observe that, in a gas turbine, excitation frequencies can result from a variety of sources. The most critical source is the mass unbalance of the rotor at a frequency $\Omega$. Coupling misalignments result in an excitation frequency of $2 \Omega$. Blades, vanes, nozzle, diffuser, and other devices produce excitation frequencies of $s \Omega$, where $s$ is the number of blades, vanes, or other devices. Bearing excitation sources can produce subharmonic excitation frequencies of $0.5 \Omega$. In the current application, there is no coupling. Therefore, $2 \Omega$ excitation frequency can be discharged. Additionally, $s \Omega$ excitation frequencies can only exist with very low energies and at very high frequencies, being also discharged. Subharmonic excitation from the bearings is not likely to occur. However, possible vibration amplitudes at $0.5 \Omega$ frequency are considered.

The rotordynamic behavior of the developed single spool gas turbine is investigated by considering the dynamic stiffness and damping coefficients of the bearings. The expected performance of the engine is to generate $5 \mathrm{kN}$ of thrust at $28,150 \mathrm{rpm}$ under international standard atmosphere conditions. The shaft of the rotor-bearing system is supported on a front bearing composed by a deep groove ball bearing with a vibration absorber element [31,32] and a rear squeeze film damper bearing $[33,34]$. Both bearings were designed to provide the appropriate stiffness and damping characteristics based on the entire rotor-bearing system. Three different radial clearances for the squeeze film damper were analyzed to determine the best configuration to avoid potential vibration problems.

\section{Single Spool Gas Turbine}

2.1. Technical Characteristics. The aeronautical gas turbine developed in this study has a single spool and is designed to be used in unmanned aerial vehicle applications. It has an air inlet duct, five-stage axial compressor, flow-through annular combustion chamber, single-stage axial turbine, and exhaustion nozzle. Figures 1(a) and 1(b) illustrate the manufactured gas turbine currently in the experimental test phase.

It should be noted that low weight and high thrust generation are highly desirable characteristics in smaller modern aircraft gas turbines. Based on user requirements, the dry weight of the developed gas turbine should be approximately $650 \mathrm{~N}$, its maximum length should not exceed $1.50 \mathrm{~m}$, and the maximum diameter of the circular section should not exceed $0.35 \mathrm{~m}$. The operation is expected for a flight envelope from 0 to $1,200 \mathrm{~m}$, maximum speeds of up to $0.9 \mathrm{Mach}$, acceleration of $10 \mathrm{~g}$ in the longitudinal axis and $7 \mathrm{~g}$ in the transverse axis, and cumulative operating time of at least $30 \mathrm{~h}$. By having a single spool, the design, manufacture, and assembly of the rotor-bearing system occur more robustly, simply, and within a shorter amount of time. The operating speed range of the gas turbine is set between 80 and $100 \%$ of the nominal speed based on the operation at the design point. Therefore, its operating speed range is set between 375.33 and $469.17 \mathrm{~Hz}$, which are the limits of the rotation speeds in which the gas turbine will mostly operate.

Figure 2 depicts a three-dimensional illustration of the cross-section of the developed gas turbine with details on the two bearings that support the rotor-bearing system. In Figure 2(a), the primary internal components of the aircraft gas turbine and its external general shape can be seen in detail, with a primary focus on the bipartite mounting of the axial compressor. The rotor-bearing system is supported by two bearings: a front or cold bearing and a rear or hot bearing. The front bearing consists of a deep groove ball bearing and a vibration absorber element. The rear bearing is an openended unsealed squeeze film damper with a circumferential feeding groove. The lubrication system has been carefully designed to meet the requirements of the bearings, which are continuously lubricated by aeronautical oil with specific performance characteristics.

2.2. Front Bearing-Deep Groove Ball Bearing. As stated previously, the front bearing of the single spool gas turbine consists of a vibration absorber element and a deep groove ball bearing. Furthermore, the front bearing is constituted by lubricating channels to transport the oil from the lubrication system. Figure 2(b) illustrates the configuration of the front bearing in detail. The deep groove ball bearing is continuously lubricated by aeronautic oil that can endure high temperature loads. In addition to lubrication, the oil dampens vibrations. The vibration absorber element provides a designed stiffness to the front bearing, which contributes to more acceptable vibration amplitudes. The stiffness of the vibration absorber element is lower than the stiffness of the deep groove ball bearing contacts and approximately constant for all rotational speeds of the rotor-bearing system. Thus, the characterization of the front bearing should be performed considering the influence of the stiffness of the vibration absorber element and the dynamic damping properties of the deep groove ball bearing contacts [9]. In [35], the procedures for characterization of the stiffness and damping dynamic coefficients of the deep groove ball bearing are presented. The stiffness coefficients of the vibration absorber element are determined by a simple structural finite element modeling and calculation using ANSYS. Table 1 lists the calculated stiffness and damping coefficients of the front bearing as a function of the rotational speed. 


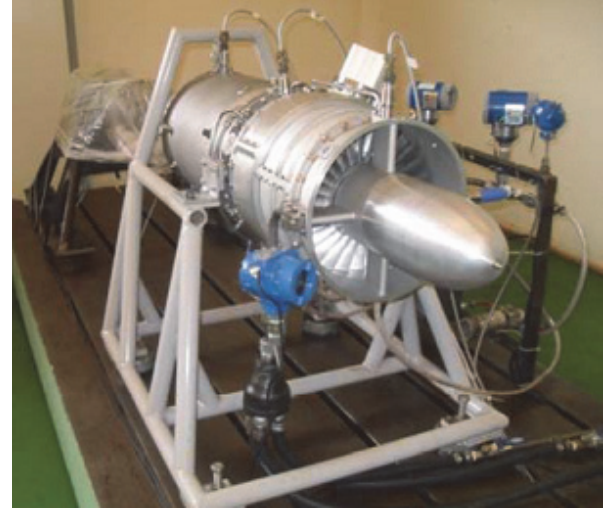

(a)

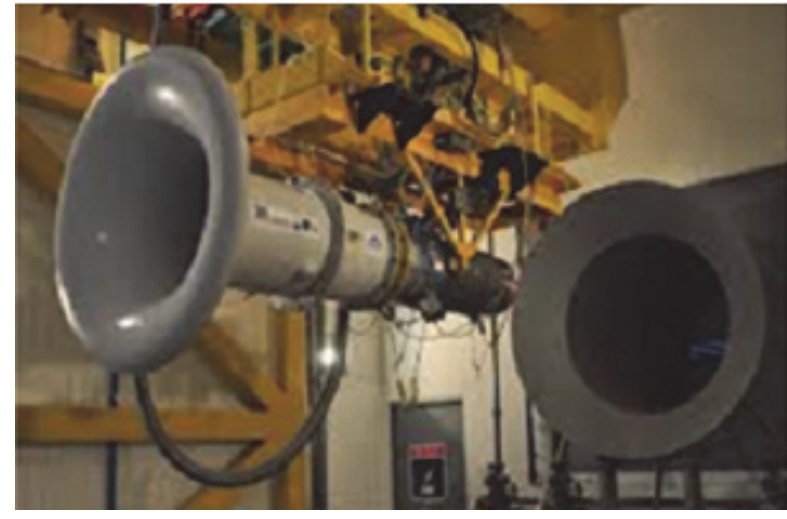

(b)

FIGURE 1: Manufactured single spool gas turbine developed in this study: (a) apparatus for demonstrative purposes and preliminary tests and (b) test rig for full test protocol.

TABLE 1: Stiffness and damping dynamics coefficients of the front bearing as a function of the rotational speed.

\begin{tabular}{lcc}
\hline $\begin{array}{l}\text { Rotational speed } \\
{[\mathrm{Hz}]}\end{array}$ & $\begin{array}{c}\text { Stiffness } \\
{[\mathrm{N} / \mathrm{m}]}\end{array}$ & $\begin{array}{c}\text { Damping } \\
{[\mathrm{Ns} / \mathrm{m}]}\end{array}$ \\
\hline 0 & $1.37 \times 10^{7}$ & 39.3 \\
83.33 & $1.37 \times 10^{7}$ & 33.4 \\
167.67 & $1.37 \times 10^{7}$ & 19.4 \\
250 & $1.37 \times 10^{7}$ & 13.5 \\
333.33 & $1.37 \times 10^{7}$ & 9.3 \\
416.67 & $1.37 \times 10^{7}$ & 7.0 \\
500 & $1.37 \times 10^{7}$ & 5.1 \\
\hline
\end{tabular}

2.3. Rear Bearing-Squeeze Film Damper. As stated previously, the rear bearing of the gas turbine consists of an unsealed squeeze film damper with a circumferential feeding groove. The type of ball bearing of the rear bearing is an angular contact. Figure 2(c) depicts the rear bearing configuration in detail. The angular contact ball bearing is continuously lubricated by aeronautic oil. The nozzle serves to improve the lubrication and cooling of the bearing. Due to the high thermal loads from the combustion chamber, the ball bearing is capable of developing small axial motions along the housing because of dilatation. Thus, there is an axial centering spring, which allows axial movement of the angular contact ball bearing without the loss of functionality. Additionally, the centering spring ensures a good contact between the balls and the pathways and prevents the rotation of the outer ring. The axial preload of the system is $150 \mathrm{~N}$. This preload affects the stiffness coefficients of the bearings. However, the variation on the stiffness coefficients caused by axial preload will not impact very much on rotordynamic results, since the axial preload of $150 \mathrm{~N}$ can be considered small according to the characteristics of the studied system (dimensions and materials). Therefore, for simplicity, axial preload has not been considered in the analysis. A radial clearance $\left(c_{r}\right)$ and an oil film of the squeeze film damper are formed between the outer surface of the external ring and the housing; that is, a radial clearance exists between the external surface of the outer ring and the housing, which is filled with oil. The circumferential feeding groove acts as a power supply of the oil, which divides the total film into two adjacent films. The groove and the adjacent oil films act as vibration absorbers to address special conditions. The geometric dimensions of the feeding groove and its interactions with the two oil film regions are considered to determine the dynamic stiffness and damping coefficients of the rear bearing. The outer ring of the angular contact ball bearing acts as a nonrotating bearing. The complete modeling of the rear bearing and the procedures for calculation of the stiffness and damping dynamic coefficients can be found in [36]. Cavitation effects by vaporization and $\pi$-film model were considered. Table 2 presents the calculated stiffness and damping dynamic coefficients of the rear bearing for three different radial clearances as a function of the rotational speed. The radial clearance is one of the most important factors used to determine the damping coefficient of a squeeze film damper, which has an optimum value for each type of application. Therefore, several computer simulations in rotordynamics were conducted to determine the influence of each radial clearance in the vibratory behavior of the developed gas turbine rotor-bearing system.

\section{Rotordynamic Model for FE Analysis}

The studied system is nonlinear; however, the modeling is linear. Despite being linear, the modeling approach allows a good representation of the studied system and the achievement of accurate rotordynamic results. The general rotordynamics equation in a stationary reference frame can be written as

$$
[M]\{\ddot{u}\}+([C]+[G])\{\dot{u}\}+([K]+[B])\{u\}=\{F\},
$$

where $[M],[C]$, and $[K]$ are the standard mass, damping, and stiffness matrices. $\{F\}$ is the external force vector which contains all the forcing functions. $[G]$ is the skew symmetric gyroscopic matrix which depends on the rotational velocity and captures the gyroscopic effect which couples rotational 
TABLE 2: Stiffness and damping dynamics coefficients of the rear bearing as a function of the rotational speed for three different radial clearances of the squeeze film damper.

\begin{tabular}{|c|c|c|c|c|c|c|}
\hline \multirow{2}{*}{$\begin{array}{l}\text { Rotational speed } \\
{[\mathrm{Hz}]}\end{array}$} & \multicolumn{2}{|c|}{$c_{r}=0.08 \mathrm{~mm}$} & \multicolumn{2}{|c|}{$c_{r}=0.12 \mathrm{~mm}$} & \multicolumn{2}{|c|}{$c_{r}=0.1905 \mathrm{~mm}$} \\
\hline & $\begin{array}{l}\text { Stiffness } \\
{[\mathrm{N} / \mathrm{m}]}\end{array}$ & $\begin{array}{c}\text { Damping } \\
{[\mathrm{Ns} / \mathrm{m}]}\end{array}$ & $\begin{array}{l}\text { Stiffness } \\
{[\mathrm{N} / \mathrm{m}]}\end{array}$ & $\begin{array}{c}\text { Damping } \\
{[\mathrm{Ns} / \mathrm{m}]}\end{array}$ & $\begin{array}{l}\text { Stiffness } \\
{[\mathrm{N} / \mathrm{m}]}\end{array}$ & $\begin{array}{l}\text { Damping } \\
{[\mathrm{Ns} / \mathrm{m}]}\end{array}$ \\
\hline 0 & $9.43 \times 10^{6}$ & 32,668 & $2.94 \times 10^{6}$ & 9,720 & $8.28 \times 10^{5}$ & 2,449 \\
\hline 83.33 & $9.43 \times 10^{6}$ & 32,668 & $2.94 \times 10^{6}$ & 9,720 & $8.28 \times 10^{5}$ & 2,449 \\
\hline 167.67 & $1.61 \times 10^{7}$ & 26,418 & $5.30 \times 10^{6}$ & 7,856 & $1.69 \times 10^{6}$ & 1,978 \\
\hline 250 & $2.01 \times 10^{7}$ & 20,352 & $7.16 \times 10^{6}$ & 6,056 & $2.60 \times 10^{6}$ & 1,529 \\
\hline 333.33 & $2.13 \times 10^{7}$ & 14,137 & $8.44 \times 10^{6}$ & 4,216 & $3.56 \times 10^{6}$ & 1,072 \\
\hline 416.67 & $2.44 \times 10^{7}$ & 11,204 & $10.5 \times 10^{6}$ & 3,352 & $4.89 \times 10^{6}$ & 859,6 \\
\hline 500 & $2.62 \times 10^{7}$ & 8,111 & $12.5 \times 10^{6}$ & 2,441 & $6.38 \times 10^{6}$ & 635,9 \\
\hline
\end{tabular}

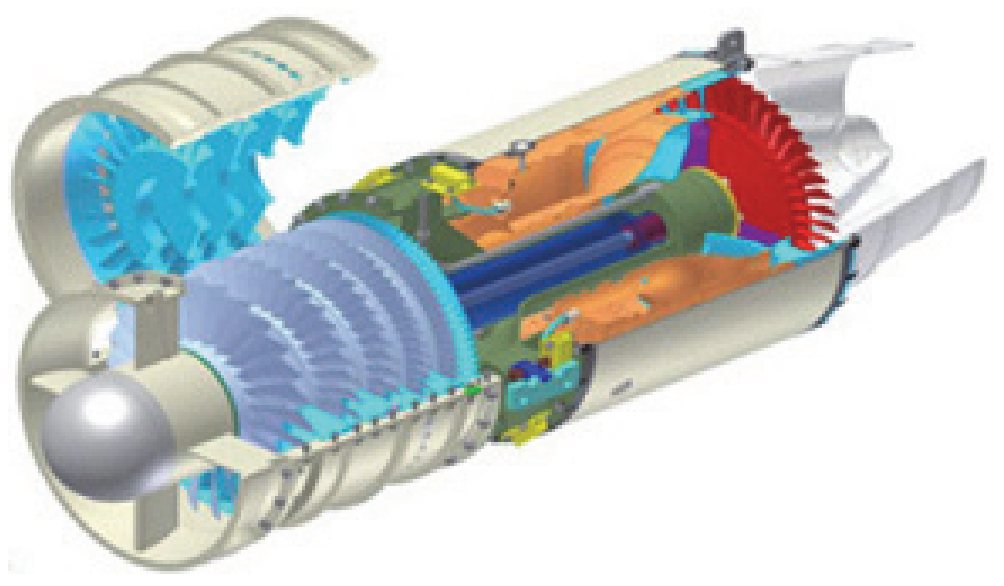

(a)

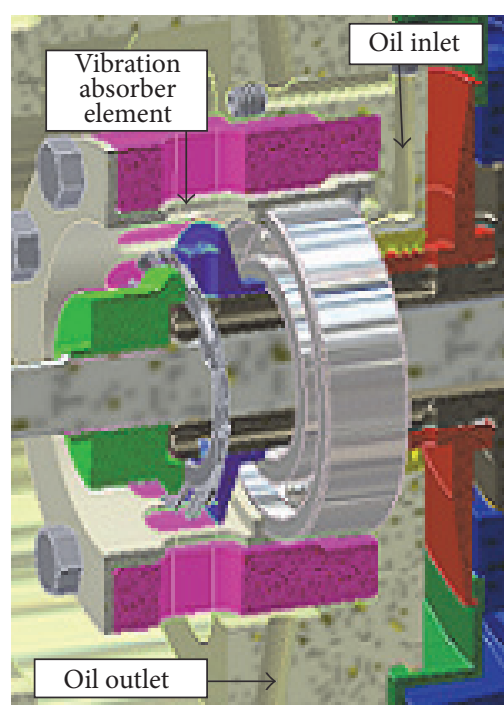

(b)

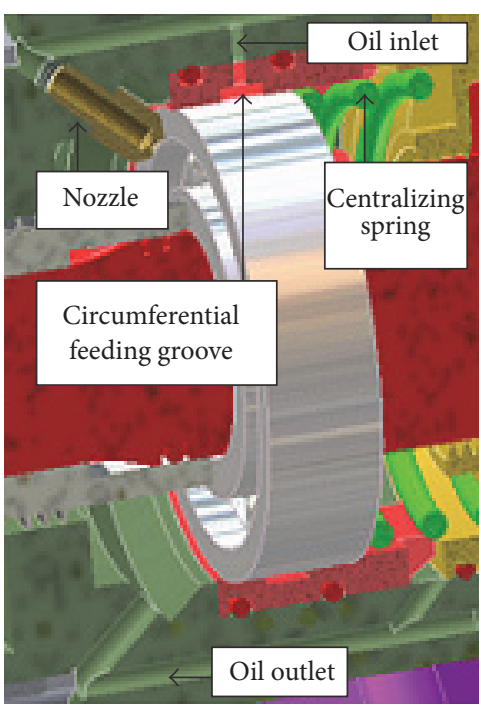

(c)

FIGURE 2: Three-dimensional illustration of the cross-section of the developed gas turbine: (a) bipartite mounting of the axial compressor and other inner components; (b) front or cold bearing; and (c) rear or hot bearing. 


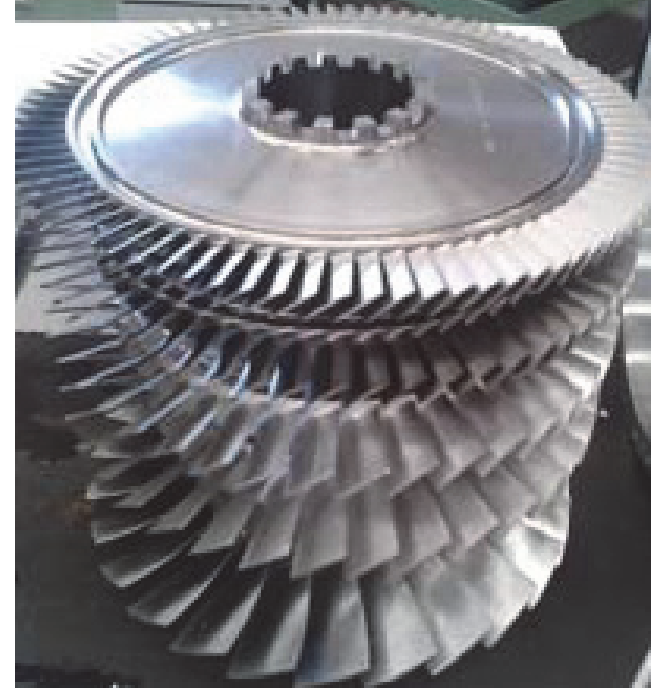

(a)

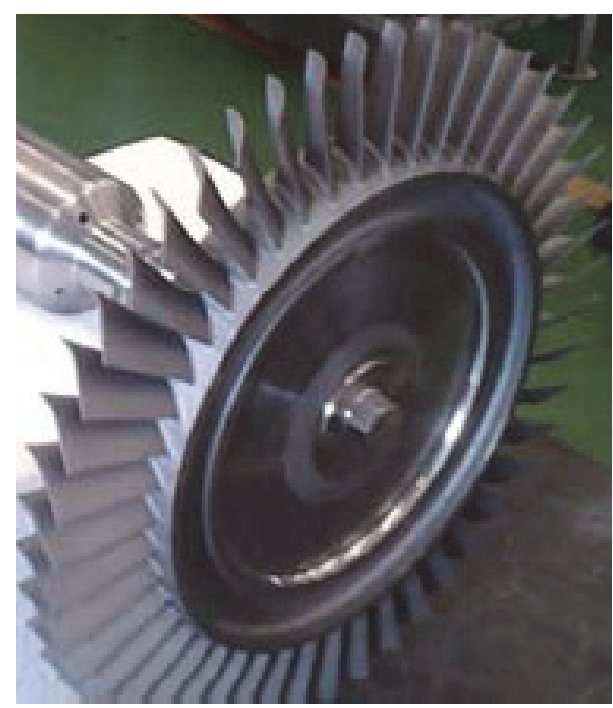

(b)

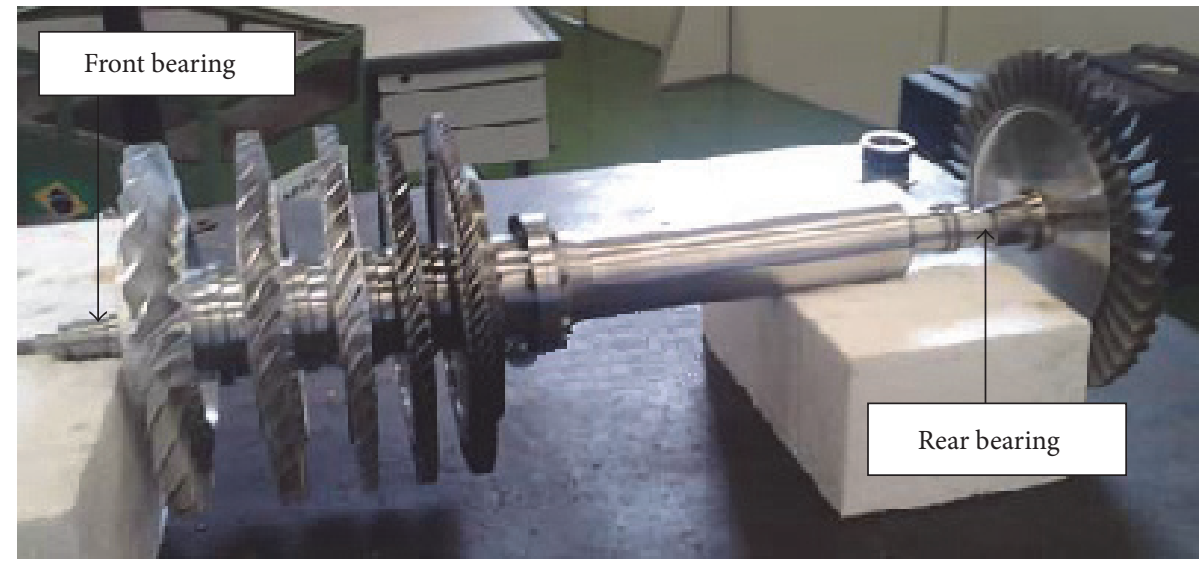

(c)

FIGURE 3: Manufactured rotor-bearing system of the developed gas turbine: (a) compressor discs; (b) free turbine disc; and (c) locations of the bearings.

degrees of freedom perpendicular to spinning axis. $[B]$ is the rotating damping matrix which also depends on rotational velocity and modifies apparent stiffness of the structure and can produce unstable motion. The classic linearized model with eight spring and damping coefficients is used to model the bearings. The forces at each bearing are assumed to obey the governing equations of the following form:

$$
\left[\begin{array}{ll}
c_{x x} & c_{x y} \\
c_{y x} & c_{y y}
\end{array}\right]\left\{\begin{array}{l}
\dot{u}_{x} \\
\dot{u}_{y}
\end{array}\right\}+\left[\begin{array}{ll}
k_{x x} & k_{x y} \\
k_{y x} & k_{y y}
\end{array}\right]\left\{\begin{array}{l}
u_{x} \\
u_{y}
\end{array}\right\}=\left\{\begin{array}{l}
f_{x} \\
f_{y}
\end{array}\right\},
$$

where $c_{i j}$ and $k_{i j}$ are the bearing damping and stiffness coefficients, respectively.

Figure 3 depicts the manufactured rotor-bearing system of the developed gas turbine with its respective discs and locations of the bearings. For the front bearing, the stiffness coefficients are given by a finite element analysis of the vibration absorber element, which is implied in $k_{y y}=k_{z z}$ and $k_{y z}=k_{z y}=0$. The stiffness coefficients $k_{y y}=k_{z z}$ are considered the same for all rotor speeds, since the variation is very small and, thus, can be neglected. The dynamic damping properties of the deep groove ball bearing are given by [35]. In a deep groove ball bearing the damping coefficients are very small. The cross-coupled terms are neglected in this study. Therefore $c_{y y}=c_{z z}$ and $c_{y z}=c_{z y}=0$. Regarding the rear bearing, the squeeze film damper used in our work is a short open-end squeeze film damper with a circumferential feeding groove. The mathematical model used to obtain the dynamic stiffness and damping coefficients has been implemented according to [36]. Only the principal force components $f_{x}$ and $f_{y}$ are calculated since it is a short open-end squeeze film damper with a circumferential feeding groove, whose design considerations assume very small eccentricity and circular synchronous centered motions. Therefore $k_{y y}=k_{z z}, c_{y y}=$ $c_{z z}$, and $k_{y z}=k_{z y}=c_{y z}=c_{z y}=0$. Tables 1 and 2 list all of the numerical values used in the calculations.

Figure 4 illustrates a schematic model for the FE analysis of the developed rotor-bearing system with its primary nodes. 


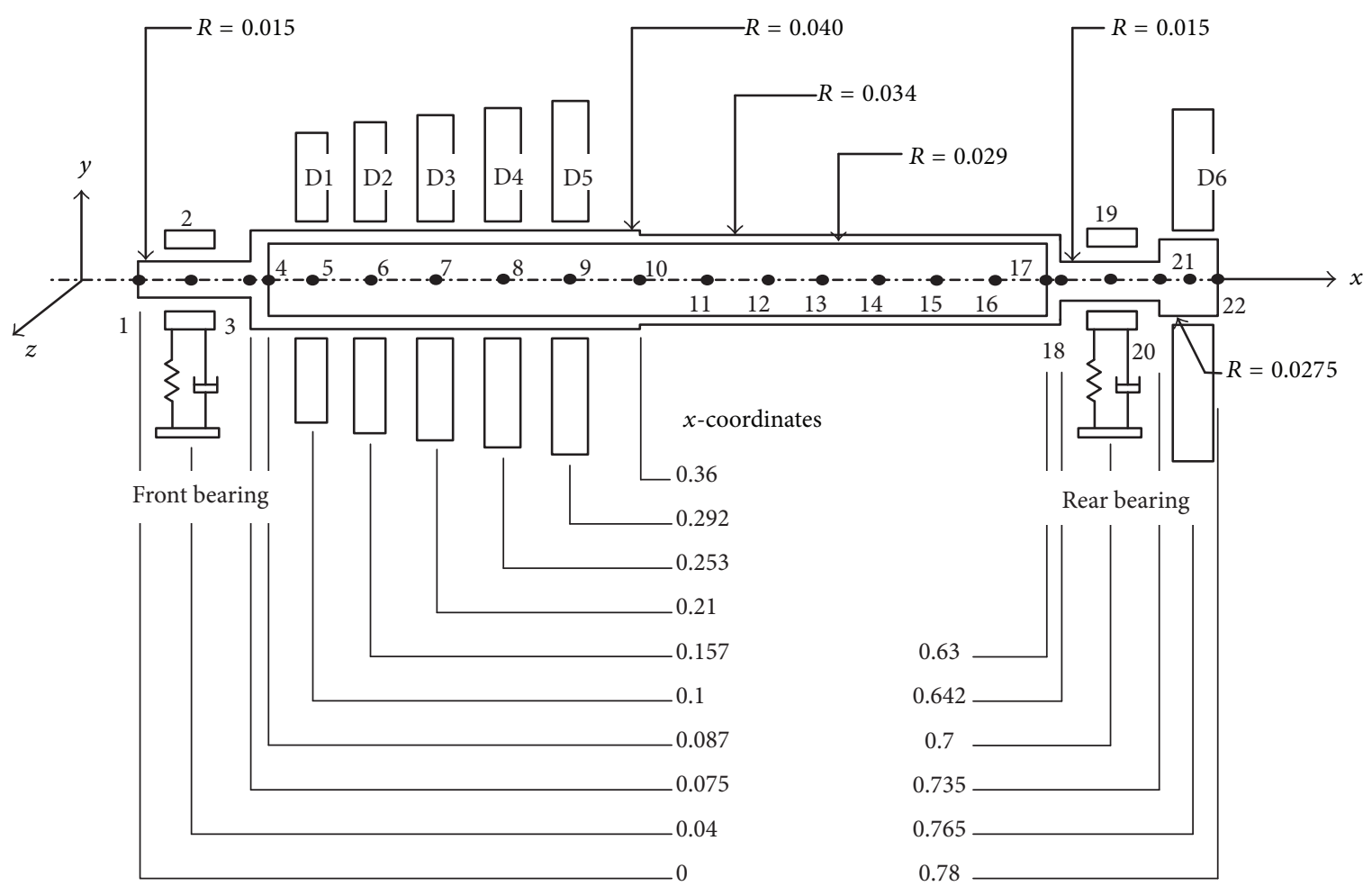

FIGURE 4: Rotor-bearing system for the FE analysis of the developed gas turbine with its primary nodes. All dimensions are in meters.

This is a simplified model because the blades and other complex geometries of the rotor-bearing system are suppressed for finite element discretization. The centers of mass and moments of inertia of the discs are considered to derive this simplified model. The shaft is made of AISI 4340 normalized steel. Young's modulus of AISI 4340 normalized steel is $205 \mathrm{GPa}$, Poisson's ratio is 0.29 , and the density is $7,850 \mathrm{~kg} / \mathrm{m}^{3}$. The discs are made of different materials to withstand the high gradient of the mechanical and thermal loads. Table 3 lists the primary physical and geometric properties of the discs. All of the discs are subjected to high centrifugal loads. The first three discs of the axial compressor are made of aluminum alloys. The fourth and fifth discs are made of titanium alloy because the temperatures above these discs are significantly higher. The sixth disc is a free turbine disc, which consists of an Inconel alloy to withstand the high temperature loads from the postcombustion gases.

The finite element model was developed using the ANSYS Parametric Design Language (APDL). The effects of the rotary inertia, gyroscopic moments, axial loads, shear deformations, and internal and external damping are included in the formulations. All of the elements in the model have 4 degrees of freedom at each node. These include translations in the nodal $y$ - and $z$-directions and rotations about the nodal $y$ - and $z$-axes. The shaft elements are modeled using Timoshenko beam quadratic elements of the type BEAM189. The discs are modeled using PIPE16 elements, which are elastic straight uniaxial elements with tension compression, torsion, and bending capabilities. The front and rear bearings are modeled using MATRIX27 elements, which are matrix elements that have an undefined geometry but an elastic kinematic response that can be specified by the stiffness and damping coefficients as a function of the rotational speed.

Due to its importance and the high degree of dangerousness of the application, it is evident that a full rotordynamic analysis needs to be performed in the rotor-bearing system considering all possible vibration problems. Initially, it is essential to verify whether the primary system critical speeds are near or far from the operating speed range. As the rotational speed approaches a critical speed of the system, the vibration levels become higher, and the existing alternating stresses also increase, thus increasing the risk of mechanical interference of the components and the occurrence of fatigue failure. Because the number of resonance points is virtually unlimited, it is necessary to assume that certain resonance points are inevitable and eliminate those that may be potentially problematic. The vibration amplitudes tend to decrease for a given vibrational motion as the frequency increases. Therefore, it is clear that the resonance points at higher frequencies have less importance. Thus, the analyst must define which resonance points should be eliminated and which ones can be tolerated. As a general rule, the resonance points in the lowest natural frequencies derived by the stronger excitation frequencies should be avoided, especially in the operating speed range, because they tend to have the greatest vibration amplitudes.

By observing Figure 3 and the schematic model of the rotor-bearing system depicted in Figure 4, it is clear that the most critical component of the rotor-bearing system is the single-stage free turbine disc (D6). This fact can be noted 
TABLE 3: Physical and geometric properties of the discs.

\begin{tabular}{lcccccc}
\hline Discs & D1 & D2 & D3 & D4 & D5 & D6 \\
\hline Material & Al7178-T6 & Al7178-T6 & Al2024-T8 & Ti-6Al-4V & Ti-6Al-4V & In713LC \\
Young's modulus, GPa & 71.7 & 71.7 & 72.4 & 113.8 & 113.8 & 163.3 \\
Density, kg/m ${ }^{3}$ & 2,830 & 2,830 & 2,870 & 4,430 & 4,430 \\
Poisson's ratio & 0.33 & 0.33 & 0.33 & 0.342 & 0.342 & 0.000 \\
Width, m & 0.02 & 0.02 & 0.02 & 0.02 & 0.02 \\
Inner diameter, m & 0.08 & 0.08 & 0.08 & 0.08 & 0.08 & 0.03 \\
Outer diameter, m & 0.19 & 0.21 & 0.23 & 0.24 & 0.25 \\
\hline
\end{tabular}

because the disc D6 is a free disc, which is located after the rear bearing. Therefore, the existence of any significant mass unbalance over this disc or any excitation of a vibration mode over the shaft will cause large amplitudes of vibration with a large possibility of fatigue failure in the region of nodes 18,19 , and 20.

\section{Results and Discussions}

A balanced quality grade G1 from the ISO standard 1940/1 was used to manufacture the rotor-bearing system. For the rotordynamic numerical analyses, a mass unbalance of $1 \times$ $10^{-4} \mathrm{~kg} \cdot \mathrm{m}$ located at node 21 of the finite element model was used. The vibration amplitudes were analyzed in both the fivestage axial compressor and the free turbine disc because the tip blade clearances of these components were defined to be as small as possible for maximum fluid dynamic efficiency.

4.1. Campbell Diagrams. The groove depth and other squeeze film damper-related parameters were kept the same for all three radial clearances $\left(c_{r}=0.08 \mathrm{~mm}, c_{r}=0.12 \mathrm{~mm}\right.$, and $c_{r}=$ $0.1905 \mathrm{~mm}$ ). The squeeze film damper with a radial clearance equal to $0.08 \mathrm{~mm}$ has the highest generated damping values. Because the bearings are symmetrical, only modes in Forward Whirl (FW) can potentially be induced. Figure 5 depicts the Campbell diagram for the radial clearance of the squeeze film damper equal to $0.08 \mathrm{~mm}$. It can be seen that, due to the high generated damping values, the natural frequencies, notably modes $1 \mathrm{FW}$ and $1 \mathrm{BW}$, have a strong nonlinearity. By considering the synchronous excitation line $(1 \Omega)$, there is only one critical speed: 2FW @ $147.1 \mathrm{~Hz}$. Other points of resonance in relation to the synchronous excitation line occur in Backward Whirl (BW) and thus cannot be induced. The critical speed of 2FW @ $147.1 \mathrm{~Hz}$ is far from the operating speed range. Other critical speeds of interest that can cause potential vibration problems are encountered when considering the $0.5 \Omega$ excitation line. The following critical speeds can be highlighted: 2FW @ 305.1 Hz and 1FW @ 360.9 Hz. Based on these critical speeds, 1FW @ $360.9 \mathrm{~Hz}$ is extremely close to the operating speed range; thus, this condition is undesirable and should be avoided.

The squeeze film damper with a radial clearance equal to $0.12 \mathrm{~mm}$ has intermediate damping values. It can be seen in the Campbell diagram in Figure 6 that the natural frequencies have less nonlinearity when compared with the natural frequencies of the diagram in Figure 5. However, there

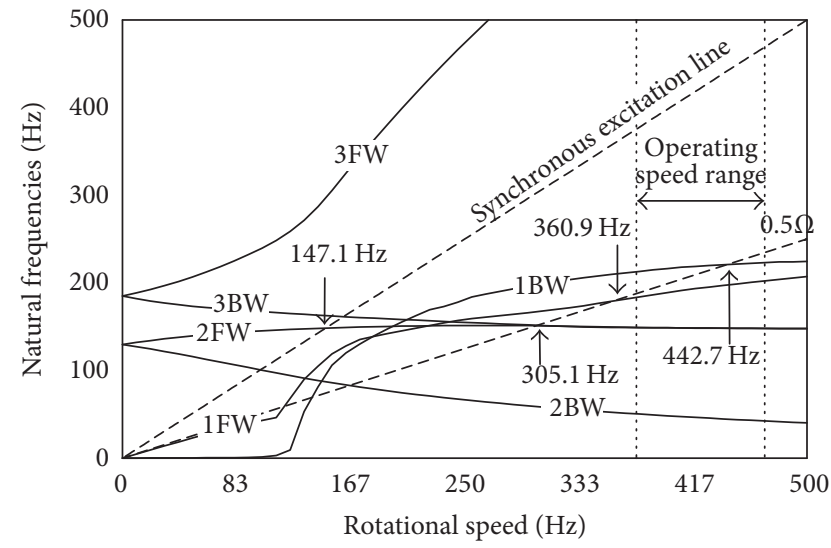

BW: backward whirl

FW: forward whirl

FIGURE 5: Campbell diagram for the radial clearance of the squeeze film damper equal to $0.08 \mathrm{~mm}$.

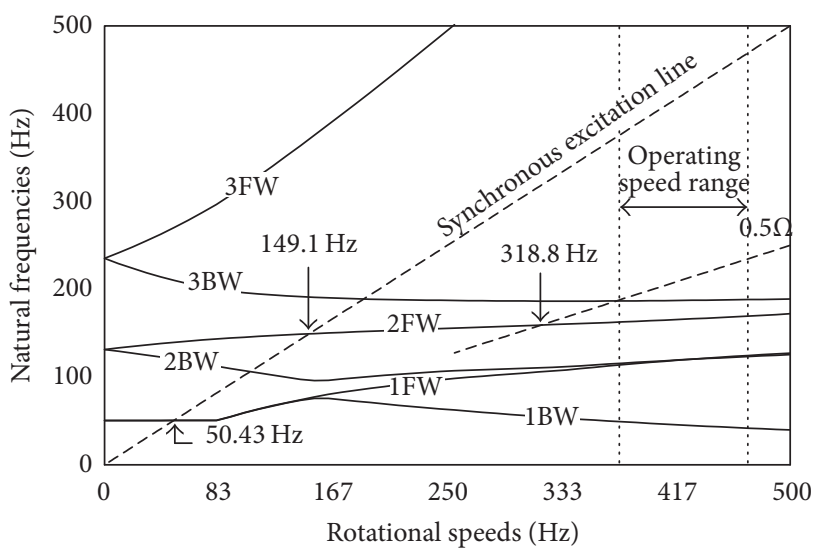

BW: backward whirl

FW: forward whirl

Figure 6: Campbell diagram for the radial clearance of the squeeze film damper equal to $0.12 \mathrm{~mm}$.

are two critical speeds when considering the synchronous excitation line: 1FW @ $50.43 \mathrm{~Hz}$ and 2FW @ 149.1 Hz. The critical speed of $2 \mathrm{FW} @ 149.1 \mathrm{~Hz}$ is far from the operating speed range and can thus be considered safe. Only one critical speed can be highlighted with respect to the $0.5 \Omega$ excitation frequency: 2FW @ $318.8 \mathrm{~Hz}$. This critical speed is outside the 


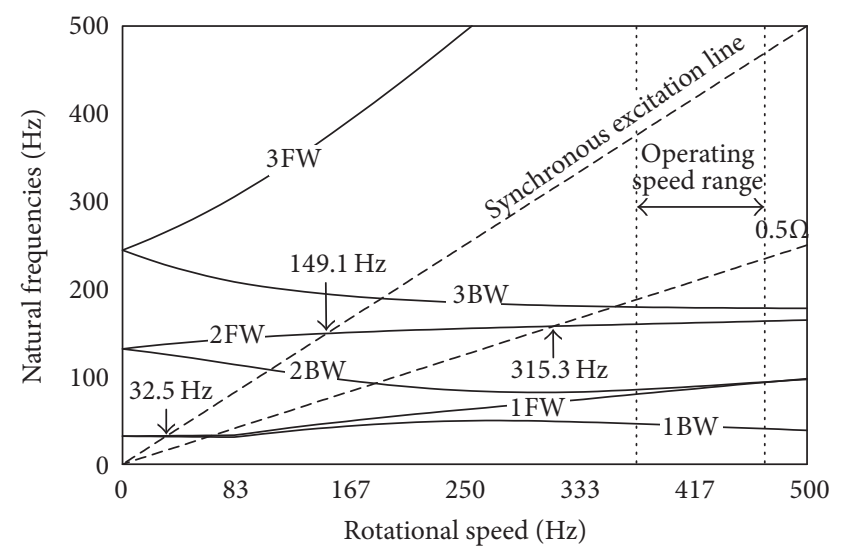

BW: backward whirl FW: forward whirl

FIgURE 7: Campbell diagram for the radial clearance of the squeeze film damper equal to $0.1905 \mathrm{~mm}$.

operating speed range by a significant margin of distance; hence, it is possible to consider it safe. There are no critical speeds within the operating speed range.

The squeeze film damper with a radial clearance equal to $0.1905 \mathrm{~mm}$ has the lowest generated damping values. It can be seen in the Campbell diagram in Figure 7 that the variation in the natural frequencies for this clearance is similar to the variation presented in the Campbell diagram in Figure 6. By considering the synchronous excitation line, the existence of two critical speeds can be observed:1FW @ $32.5 \mathrm{~Hz}$ and 2FW @ $149.1 \mathrm{~Hz}$. The critical speed of 2FW @ $149.1 \mathrm{~Hz}$ is far from the operating speed range and can thus be considered safe. Only one critical speed can be highlighted with respect to the $0.5 \Omega$ excitation frequency: 2FW @ $315.3 \mathrm{~Hz}$. This critical speed is outside the operating speed range by a significant margin of distance. Therefore, it can be considered safe. There are no critical speeds within the operating speed range.

By considering the Campbell diagrams presented for the three different radial clearances, it should be noted that the critical speeds that could result from the intersections of the natural frequencies with respect to the $2 \Omega$ excitation line were not considered in the analyses because there is no coupling in the rotating shaft, and this $2 \Omega$ excitation frequency is thus unlikely to occur with significant levels of energy. Furthermore, the other critical speeds with respect to the $s \Omega$ excitation lines were discharged because they only can appear at extremely high frequencies and hence have very low amplitudes of vibration. These excitation frequencies have limited possibilities of existing with significant levels of energy to cause vibration problems in the system.

4.2. Unbalanced Responses. Figure 8 illustrates the unbalanced responses of the rotor-bearing system when the radial clearance of the squeeze film damper equals $0.08 \mathrm{~mm}$. It is possible to see that the critical speed of $2 \mathrm{FW} @ 147.1 \mathrm{~Hz}$ is the most troublesome. The vibration amplitudes were analyzed at the five-stage axial compressor and the free turbine disc. The vibration amplitudes reached $5.4 \mu \mathrm{m}$ at the axial compressor region and $11.2 \mu \mathrm{m}$ at the single-stage free turbine disc for an operating speed range of 22,520 to $28,150 \mathrm{rpm}$. The vibration amplitudes due to the critical speed of 2FW @ $147.1 \mathrm{~Hz}$ reached $117.6 \mu \mathrm{m}$ over the axial compressor region and $58.1 \mu \mathrm{m}$ at the single-stage turbine disc.

Figure 9 depicts the unbalanced responses of the rotorbearing system when the radial clearance of the squeeze film damper equals $0.12 \mathrm{~mm}$. It is possible to see that the critical speed of 1FW @ $50.43 \mathrm{~Hz}$ is largely attenuated by the damping performance of the squeeze film damper. The critical speed of 2FW@149.1 Hz is the most troublesome. The vibration amplitudes reached $5.9 \mu \mathrm{m}$ at the five-stage axial compressor region and $8.6 \mathrm{~mm}$ at the single-stage free turbine disc for an operating speed range of 22,520 to $28,150 \mathrm{rpm}$. The vibration amplitudes due to the critical speed of 2FW @ $149.1 \mathrm{~Hz}$ reached $189.1 \mathrm{~mm}$ at the five-stage axial compressor region and $113.3 \mathrm{~mm}$ at the free turbine disc region.

Figure 10 depicts the unbalanced responses of the rotorbearing system when the radial clearance of the squeeze film damper equals $0.1905 \mathrm{~mm}$. It is possible to observe the presence of an amplitude peak related to the critical speed of 1FW @ $32.5 \mathrm{~Hz}$. This peak occurs due to the lower generated damping values of the squeeze film damper with a radial clearance of $0.1905 \mathrm{~mm}$. The critical speed of 2FW @ $149.1 \mathrm{~Hz}$ is the most troublesome. The vibration amplitudes reached $6.2 \mu \mathrm{m}$ at the five-stage axial compressor region and $8.0 \mu \mathrm{m}$ at the singlestage free turbine disc region for an operating speed range of 22,520 to $28,150 \mathrm{rpm}$. The vibration amplitudes due to the critical speed of 1FW@ $32.5 \mathrm{~Hz}$ reached $5.0 \mu \mathrm{m}$ for the fivestage axial compressor region and $11.5 \mu \mathrm{m}$ for the free turbine disc. The vibration amplitudes due to the critical speed of 2FW@149.1 Hz reached $329.5 \mu \mathrm{m}$ at the axial compressor region and $190.7 \mu \mathrm{m}$ at the single-stage free turbine disc.

4.3. Transient Responses. Transient analyses were performed to simulate the transition of the rotor-bearing system through the primary resonance points. A linear acceleration model is considered for the system $\left(\omega=\omega_{0}+\alpha t\right)$. The angular acceleration during the acceleration phase of the system is set to $314.15 \mathrm{rad} / \mathrm{s}^{2}$, since a time of about 10 seconds for the aeronautical gas turbine to reach maximum rotational speed is expected. Figure 11 depicts the total displacement at node 21 of the rotor-bearing system when the radial clearance is $0.08 \mathrm{~mm}$ for the squeeze film damper. The total displacement is obtained by the sum of the horizontal displacement $(z)$ and the vertical displacement $(y)$. A slight salience appears in the solution approximately 6.45 seconds after starting the gas turbine. This salience is related to the critical speed of 2FW@ @ $305.1 \mathrm{~Hz}$ for the $0.5 \Omega$ excitation frequency. This result can be observed by the Campbell diagram in Figure 5. This amplitude of vibration at the $0.5 \Omega$ frequency occurs smoothly due to the high damping performance of the squeeze film damper with a radial clearance of $0.08 \mathrm{~mm}$. The vibration amplitudes during the passage through the resonance point of 2FW@147.1 Hz reached $26.6 \mu \mathrm{m}$, thus demonstrating the strong attenuation by the rear bearing with $0.08 \mathrm{~mm}$ of radial clearance.

Figure 12 depicts the transient response of the rotorbearing system for a radial clearance of $0.12 \mathrm{~mm}$ for the total 


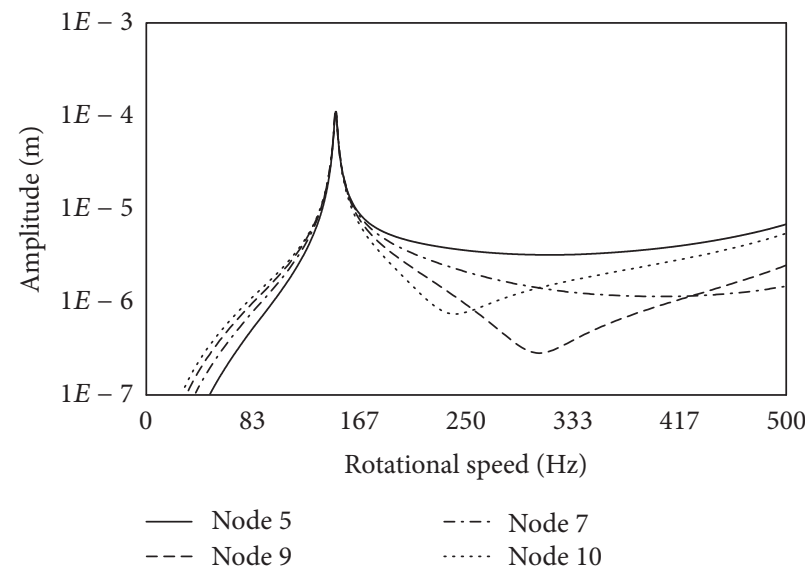

(a)

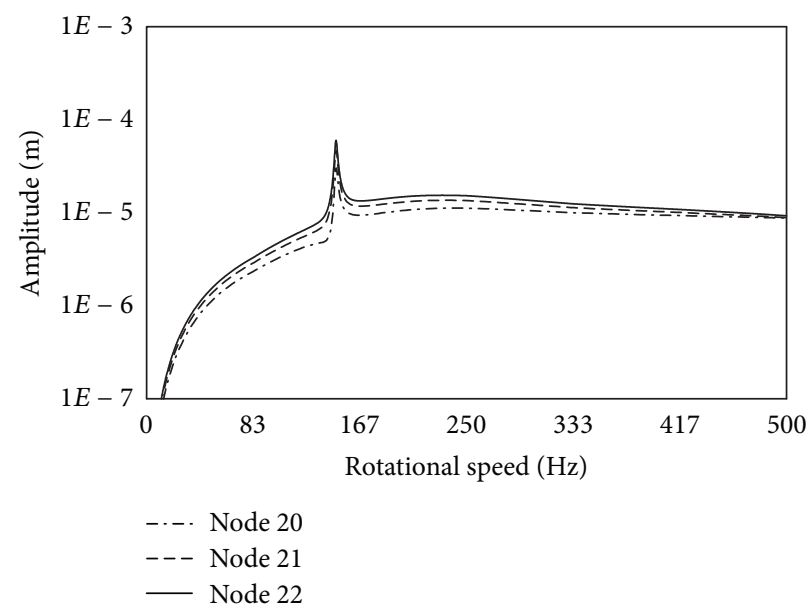

(b)

FIGURE 8: Unbalanced responses of the rotor-bearing system for the radial clearance of the squeeze film damper equal to $0.08 \mathrm{~mm}$.

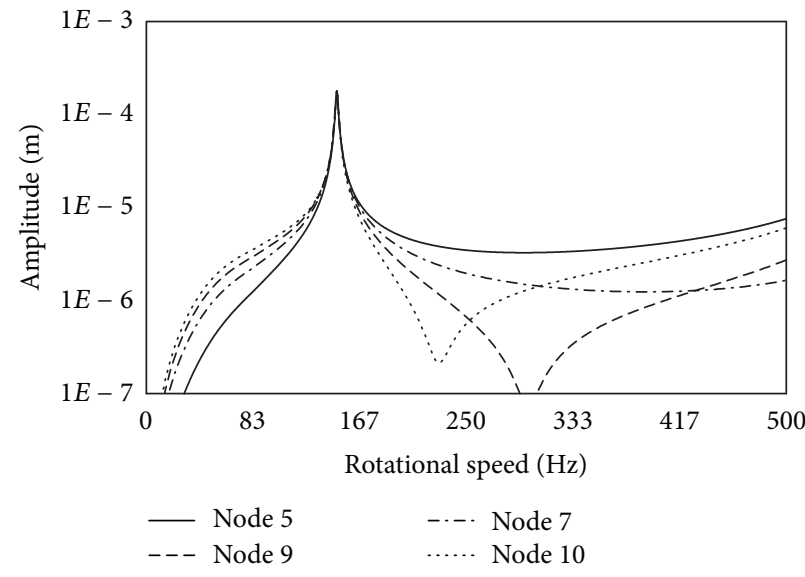

(a)

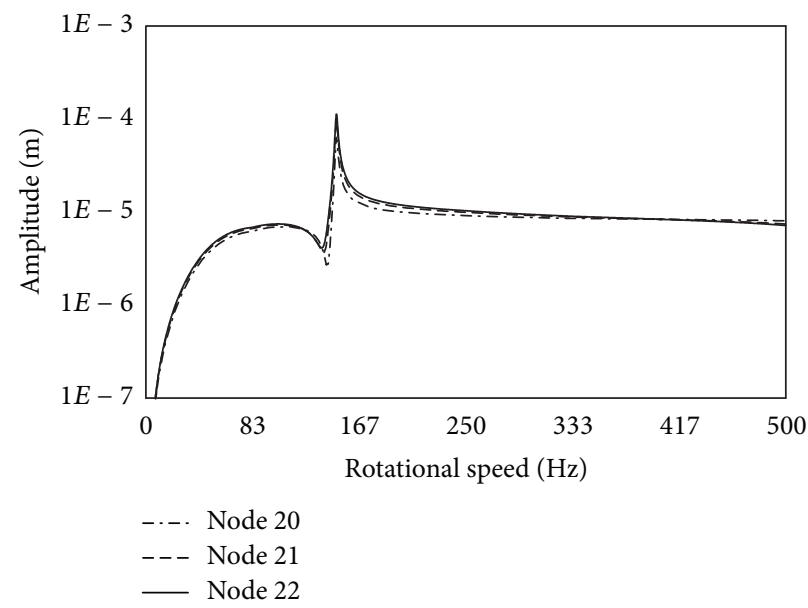

(b)

FIGURE 9: Unbalanced responses of the rotor-bearing system for the radial clearance of the squeeze film damper equal to $0.12 \mathrm{~mm}$.

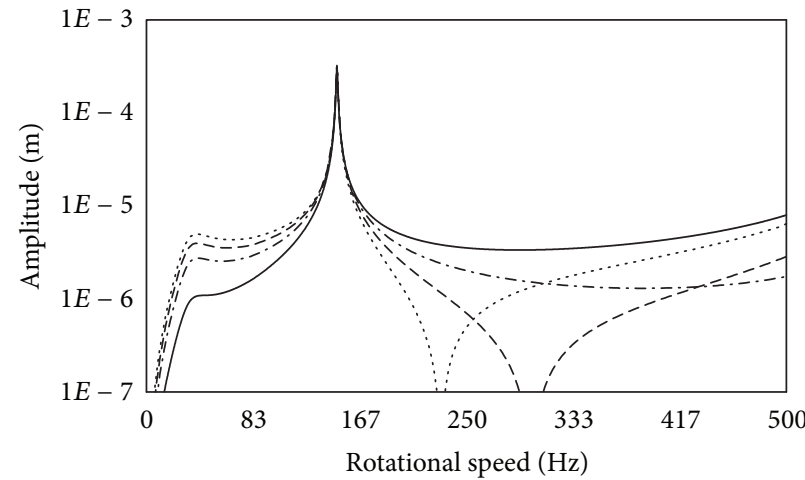

- Node 5

-... Node 7

...... Node 10

(a)

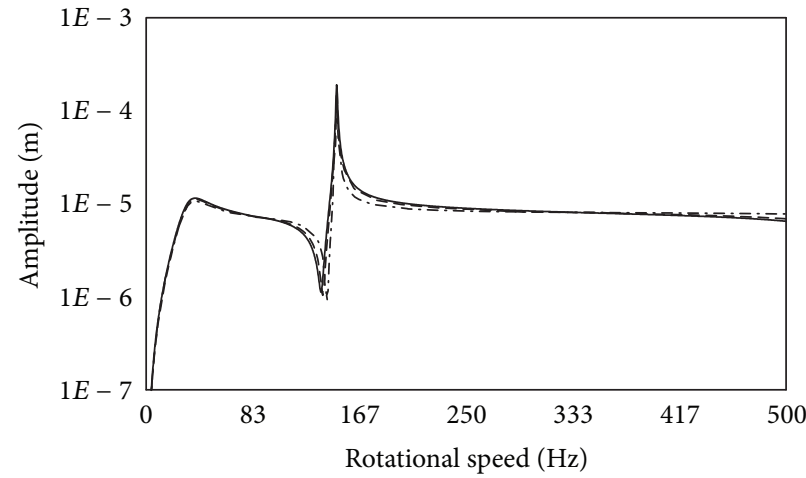

-.-. Node 20

- - Node 21

— Node 22

FIGURE 10: Unbalanced responses of the rotor-bearing system for the radial clearance of the squeeze film damper equal to $0.1905 \mathrm{~mm}$. 


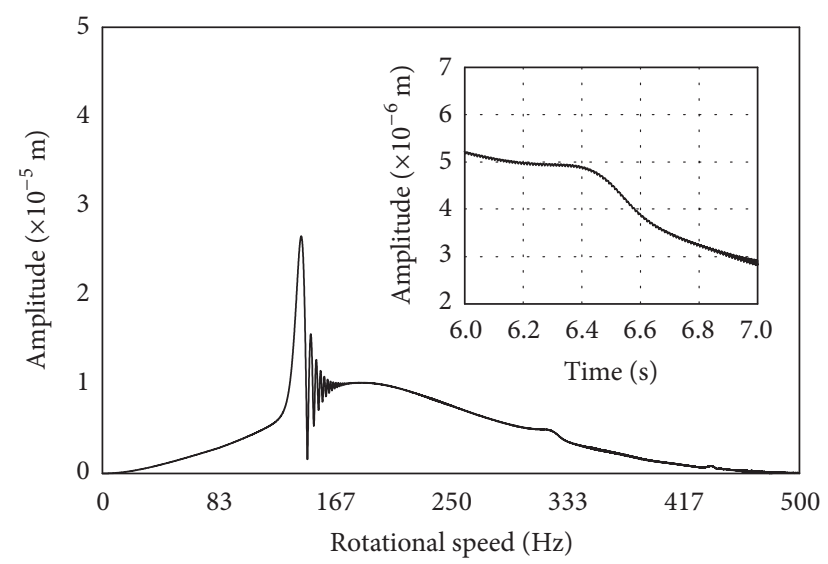

FIGURE 11: Total displacement at node 21 of the rotor-bearing system for the radial clearance of the squeeze film damper equal to $0.08 \mathrm{~mm}$.

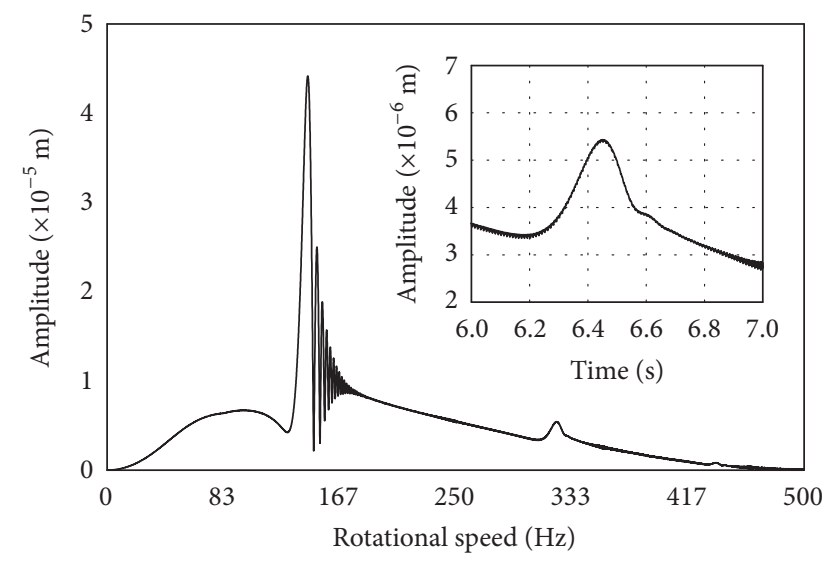

FIGURE 12: Total displacement at node 21 of the rotor-bearing system for the radial clearance of the squeeze film damper equal to $0.12 \mathrm{~mm}$.

displacements at node 21. A small peak appears in the solution approximately 6.45 seconds after the gas turbine starts up. This small peak is related to the critical speed of 2FW @ $318.8 \mathrm{~Hz}$ for the $0.5 \Omega$ excitation frequency. This result can be observed by the Campbell diagram in Figure 6. This vibration at the $0.5 \Omega$ frequency occurs smoothly due to the damping performance of the squeeze film damper for a radial clearance of $0.12 \mathrm{~mm}$. The vibration amplitudes during the passage through the resonance point of 2FW @ $149.1 \mathrm{~Hz}$ reached $44.2 \mu \mathrm{m}$.

Figure 13 depicts the transient response of the rotorbearing system for a radial clearance of $0.1905 \mathrm{~mm}$ for the total displacements at node 21. A significant peak appears in the solution approximately 6.45 seconds after the gas turbine starts up. This peak is related to the critical speed of $2 \mathrm{FW}$ @ $315.3 \mathrm{~Hz}$ for the $0.5 \Omega$ excitation frequency. This result can be observed by the Campbell diagram in Figure 7. This amplitude of vibration at the $0.5 \Omega$ frequency occurs in a significant manner due to the low damping performance of the squeeze film damper with a radial clearance of $0.1905 \mathrm{~mm}$. The vibration amplitudes during the passage through the resonance point of $1 \mathrm{FW} @ 32.5 \mathrm{~Hz}$ reached $11.3 \mu \mathrm{m}$. The

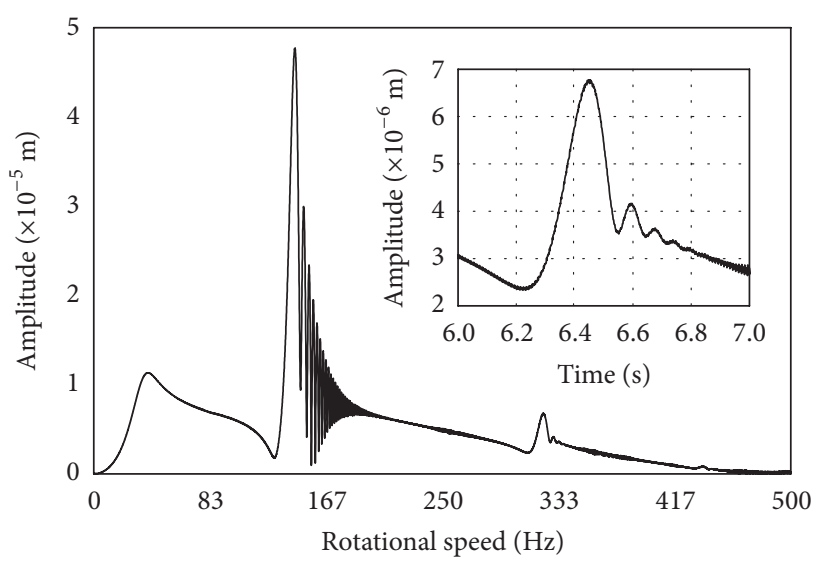

FIgURE 13: Total displacement at node 21 of the rotor-bearing system for the radial clearance of the squeeze film damper equal to $0.1905 \mathrm{~mm}$.

vibration amplitudes reached $47.7 \mu \mathrm{m}$ for the resonance point of 2PD @ $149.1 \mathrm{~Hz}$.

4.4. Selection of the Squeeze Film Damper. From the analysis presented above, it is possible to select the best radial clearance for the squeeze film damper and, consequently, the best combination of bearings for the rotor-bearing system. It is clear that, for a radial clearance of $0.08 \mathrm{~mm}$, the greatest attenuation occurs in the amplitudes of the response. Nevertheless, for a clearance of $0.08 \mathrm{~mm}$, the $1 \mathrm{FW}$ at $360.9 \mathrm{~Hz}$ resonance point is extremely close to the operating range. Comparing the numerical analyses for the clearances of 0.12 and $0.1905 \mathrm{~mm}$, it is possible to see that the Campbell diagrams for these two conditions are similar. However, because the $0.12 \mathrm{~mm}$ radial clearance provides higher damping values, the first critical speed with respect to the synchronous excitation line is considerably reduced, thus making it unnoticeable. Additionally, the unbalanced response amplitudes indicated lower values compared to the $0.1905 \mathrm{~mm}$ radial clearance. Thus, although the response amplitudes for the radial clearance of $0.1905 \mathrm{~mm}$ is also acceptable, considering the tip clearances, the radial clearance of $0.12 \mathrm{~mm}$ was selected to be used in the design of the squeeze film damper of the rear bearing of the developed single spool gas turbine to ensure a greater safety margin for the system.

4.5. Stability Analysis of the System. It is of fundamental importance to predict the stability of the rotor-bearing system from rest to maximum speed. One way to check the dynamic stability of a rotor-bearing system is to calculate the logarithmic decrements in their respective natural frequencies. During the Campbell diagram calculations, the ANSYS software provides the real and imaginary parts of the natural frequencies and the respective damping rate. The calculation of the logarithm decrement $\xi$ is done as a function of the damping rate $\zeta$, according to the following equation:

$$
\xi=\sqrt{\frac{4 \pi^{2}}{(1 / \zeta)^{2}-1}} .
$$


TABLE 4: Logarithmic decrements calculated for the six first natural frequencies of the rotor-bearing system.

\begin{tabular}{|c|c|c|c|c|c|c|}
\hline $\begin{array}{l}\text { Rotational speed } \\
{[\mathrm{Hz}]}\end{array}$ & $\begin{array}{l}1 \mathrm{FW} \\
\text { mode }\end{array}$ & $\begin{array}{l}1 \mathrm{BW} \\
\text { mode }\end{array}$ & $\begin{array}{l}2 \mathrm{FW} \\
\text { mode }\end{array}$ & $\begin{array}{l}2 \mathrm{BW} \\
\text { mode }\end{array}$ & $\begin{array}{l}3 \mathrm{FW} \\
\text { mode }\end{array}$ & $\begin{array}{l}\text { 3BW } \\
\text { mode }\end{array}$ \\
\hline 55.56 & 5.0437 & 5.2713 & 0.2024 & 0.0216 & 0.8447 & 0.8903 \\
\hline 111.11 & 3.3526 & 3.8727 & 0.4609 & 0.0234 & 0.7276 & 0.7742 \\
\hline 166.67 & 1.0670 & 2.4758 & 1.3331 & 0.0453 & 0.6332 & 0.5997 \\
\hline 222.22 & 0.3705 & 1.7818 & 1.3666 & 0.0743 & 0.5428 & 0.4473 \\
\hline 277.78 & 0.1605 & 1.2929 & 1.0972 & 0.1012 & 0.4522 & 0.3222 \\
\hline 333.33 & 0.0779 & 0.9097 & 0.8126 & 0.1171 & 0.3563 & 0.2216 \\
\hline 388.89 & 0.0419 & 0.6765 & 0.6255 & 0.1460 & 0.3253 & 0.1705 \\
\hline 444.44 & 0.0256 & 0.4636 & 0.4822 & 0.1671 & 0.2886 & 0.1283 \\
\hline 500 & 0.0171 & 0.3288 & 0.3251 & 0.1720 & 0.2445 & 0.0934 \\
\hline
\end{tabular}

It is well known that internal damping can destabilize a rotorbearing system. Furthermore, numerical formulations, which include hysteretic damping effects, can occasionally lead to incorrect prediction system instability ranges. Therefore, in this work we calculate the values of the logarithmic decrements throughout the rotational speed. The instabilities are determined when the values of the logarithmic decrements are less than zero. Table 4 presents the logarithmic decrements calculated for the first six natural frequencies of the system. As seen in Table 4, there is no occurrence of instabilities because all of the logarithmic decrements in the system are positive.

4.6. Alternating Bending Stresses. The alternating bending stresses were evaluated at several specific points of the rotorbearing system. From Figure 4, it can be seen that node 20 is located in one of the most critical locations; that is, it is located after the rear bearing and before the free turbine disc. Additionally, node 20 is situated in a region with a significant transition in the cross-section area. The smallest crosssectional area of the shaft is located at this node. Figure 14 depicts the alternating bending stress calculated at node 20 during the transition through the primary resonance points of the rotor-bearing system. As shown, extremely low stress values were found throughout the transient acceleration phase of the gas turbine. The greatest stress values on node 20 occur during the passage through the second critical speed, which is $4.4 \mathrm{MPa}$. For the critical speed with respect to the $0.5 \Omega$ excitation line, the magnitude of the alternating bending stresses can reach 1.7 MPa. By assuming that the gas turbine acceleration phase has been completed, it can be observed that the alternating bending stresses within the operating speed range of the gas turbine will not exceed 1.8 $\mathrm{MPa}$. These stress values are extremely low considering the material and dimensions of the shaft cross-section. Thus, the service life of the shaft will not be compromised. Therefore, an infinite life of the shaft to fatigue failure can be expected. The alternating bending stresses calculated for other nodes of the shaft indicated lower values and were less significant.

4.7. Spectral Map of the Rotor-Bearing System. In addition to the analyses presented above, it is also important to plot

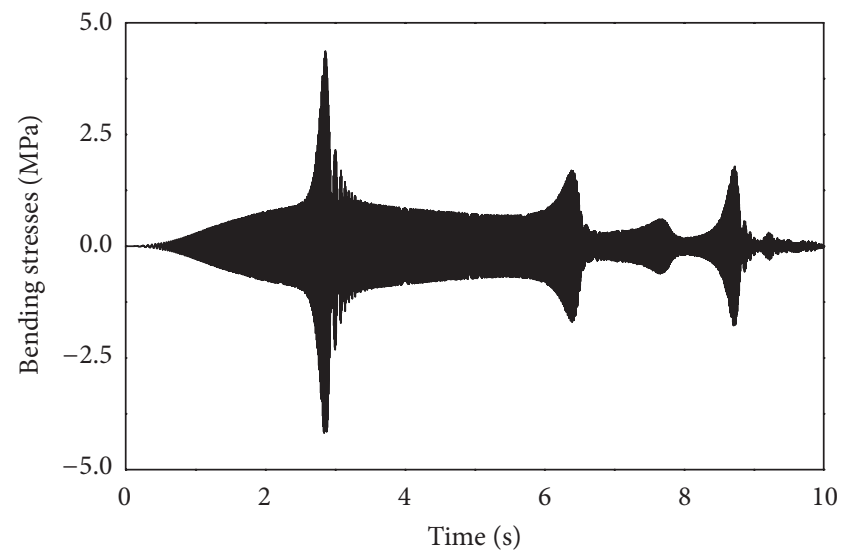

FIGURE 14: Alternating bending stresses evaluated at node 20 during the system transition through resonance.

the spectral map of the rotor-bearing system considering a broader range of excitation frequencies. In this spectral map, the vibration amplitudes, which are given by unbalance responses, are plotted as a function of the rotational speed and of the various excitation frequencies that may exist in the system. The number of excitation frequencies and intervals between the values of the rotational speeds are defined by the amount of substeps. Thus, the regions where the amplitudes of vibration are undesirable can be defined, considering the interaction between the rotational speeds and excitation frequencies. Figure 15 illustrates the spectral map of the rotorbearing system when the radial clearance of the squeeze film damper is equal to $0.12 \mathrm{~mm}$. It was considered that the rotational speed of the rotor-bearing system ranges from 0 to $500 \mathrm{~Hz}$ in intervals of 50 substeps. The excitation frequencies range from 0 to $500 \mathrm{~Hz}$ in 250 substep intervals. The vibration amplitudes are calculated on node 21 using clusters with $5 \mathrm{~Hz}$ of bandwidth and a minimum frequency of $0.5 \mathrm{~Hz}$. The higher vibration amplitudes occur due to the second critical speed. The first critical speed can be observed in the rotational speed of the rotor-bearing system at $500 \mathrm{~Hz}$, with an excitation frequency of $125 \mathrm{~Hz}$. The $0.5 \Omega$ subharmonic vibrations may be observed at a rotational speed of approximately $330 \mathrm{~Hz}$ with an excitation frequency of $500 \mathrm{~Hz}$. It can be seen in 


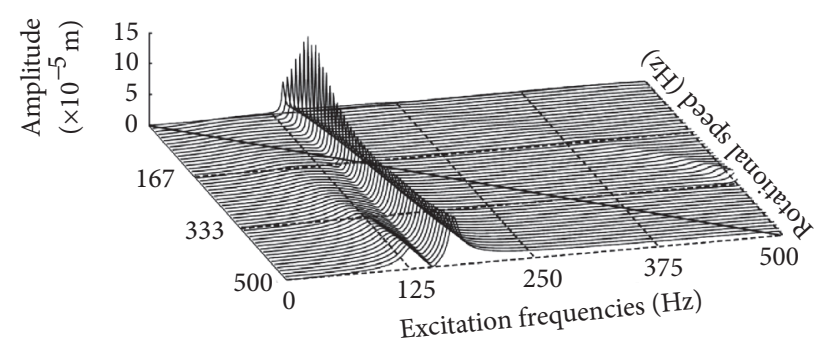

FIGURE 15: Spectral map of the developed rotor-bearing system.

the spectral map that the operating speed range of the rotorbearing system is free from undesirable vibration amplitudes in all excitation frequencies and rotational speeds of interest.

\section{Conclusions}

It was observed that the radial clearance of the squeeze film damper strongly influence the damping performance of the rear bearing. For smaller values of radial clearance, the damping generated in the bearing is higher, as described in literature. Regarding the oil viscosity, the bearing damping capacity decreases with the oil temperature because the lubricating oil loses viscosity as the temperature increases. With respect to the bearing stiffness, as the viscosity of the lubricant decreases, the bearing stiffness increases. From the Campbell diagrams, unbalanced responses, and transient analyses, the radial clearance of $0.12 \mathrm{~mm}$ proved to be the most suitable for the developed single spool gas turbine squeeze film damper and was thus used for the final design of the rear bearing. With respect to the system stability analysis, the logarithmic decrements were calculated, and there was no occurrence of instabilities. Furthermore, the shaft alternating bending stresses were evaluated during the acceleration phase of the rotor-bearing system. Extremely low values for the bending stresses were observed during the passage through the resonance points. Thus, the fatigue life of the shaft is expected to be infinite. With respect to the spectral map of the rotorbearing system, it can be concluded that the operating speed range is free from undesirable vibration amplitudes considering all excitation frequencies of interest. A good agreement among the results could be verified in all numerical analyses, the rotordynamic behavior of the developed single spool gas turbine was predicted, and potential vibration problems were avoided. The finite element analyses were strictly evaluated and the mechanical drawings of the aeronautical gas turbine were released to manufacturing. The first prototype is in its final experimental test phase and indicates that the performance on the test rig is consistent with the behavior indicated by the rotordynamic numerical analysis presented in this paper.

\section{Competing Interests}

The authors declare that there is no conflict of interests regarding the publication of this paper.

\section{Acknowledgments}

The authors would like to thank Instituto Tecnológico de Aeronáutica and TGM Turbinas Ltda for all the support given to develop this project. The first three authors would like to thank Instituto Federal de Educação, Ciência e Tecnologia de São Paulo (IFSP-BRA), for the opportunity to collaborate in this project. The fourth author would like to thank Universidade Estadual de Campinas (Unicamp-FEM) for the opportunity to participate in this project as part of his postdoctoral studies. Additionally, the first and fifth authors would like to thank CAPES and CNPq 385582/2006-4 for their financial support.

\section{References}

[1] C. Bringhenti, J. T. Tomita, and J. R. Barbosa, "Gas turbine course's teaching process at instituto tecnológico de aeronáutica: theory and laboratory," Journal of Aerospace Technology and Management, vol. 7, no. 1, pp. 110-120, 2015.

[2] J. T. Tomita, L. P. Bontempo, and J. R. Barbosa, "An axial flow compressor for operation with humid air and water injection," Journal of Engineering for Gas Turbines and Power, vol. 133, no. 7, Article ID 071703, 2011.

[3] J. T. Tomita, C. Bringhenti, J. R. Barbosa, and V. A. Carlesse, "Performance evaluation of a $5 \mathrm{kN}$ gas turbine based on specially designed components," in Proceedings of the ASME Turbo Expo 2012: Turbine Technical Conference and Exposition, vol. 3, pp. 449-456, 2012, Paper No. GT2012-70020.

[4] J. T. Tomita, J. R. Barbosa, and C. Bringhenti, "The flow machines course at the Technological Institute of Aeronautics for Mechanical-Aeronautical Engineering undergraduate course," in Proceedings of the ASME Turbo Expo 2013: Turbine Technical Conference and Exposition, vol. 4, 2013, Paper No. GT201395228.

[5] R. Walker, S. Perinpanayagam, and I. K. Jennions, "Rotordynamic faults: recent advances in diagnosis and prognosis," International Journal of Rotating Machinery, vol. 2013, Article ID 856865, 12 pages, 2013.

[6] D. Laxalde and C. Pierre, "Modelling and analysis of multi-stage systems of mistuned bladed disks," Computers and Structures, vol. 89, no. 3-4, pp. 316-324, 2011.

[7] S. M. Jeon, H. D. Kwak, S. H. Yoon, and J. Kim, "Rotordynamic analysis of a turbopump with the casing structural flexibility," Journal of Propulsion and Power, vol. 24, no. 3, pp. 433-436, 2008.

[8] B. D. Thompson and J. Grobler, "Development US Navy Gas Turbine vibration analysis expertise: $501-\mathrm{K}$ vibration and remote monitoring of gas turbine vibration," in Proceedings of ASME Turbo Expo 2012: Turbine Technical Conference and Exposition, vol. 5, pp. 255-263, 2012, Paper No. GT2012-68255.

[9] G. Creci, J. C. Menezes, J. R. Barbosa, and J. A. Corrá, “Rotordynamic analysis of a 5-kilonewton thrust gas turbine by considering bearing dynamics," Journal of Propulsion and Power, vol. 27, no. 2, pp. 330-336, 2011.

[10] G. Creci, Influência da dinâmica dos mancais na resposta vibratória de uma turbina aeronáutica de 5-kN de empuxo [Ph.D. thesis], 2012 (Portuguese), http://www.bdita.bibl.ita.br/tesesdigitais. 
[11] R. U. Mendes and K. L. Cavalca, "On the instability threshold of journal bearing supported rotors," International Journal of Rotating Machinery, vol. 2014, Article ID 351261, 17 pages, 2014.

[12] M. Kalita and S. K. Kakoty, "Analysis of whirl speeds for rotorbearing systems supported on fluid film bearings," Mechanical Systems and Signal Processing, vol. 18, no. 6, pp. 1369-1380, 2004.

[13] H.-W. D. Chiang, C.-N. Hsu, and S.-H. Tu, "Rotor-bearing analysis for turbomachinery single- and dual-rotor systems," Journal of Propulsion and Power, vol. 20, no. 6, pp. 1096-1104, 2004.

[14] D. Combescure and A. Lazarus, "Refined finite element modelling for the vibration analysis of large rotating machines: application to the gas turbine modular helium reactor power conversion unit," Journal of Sound and Vibration, vol. 318, no. 4-5, pp. 1262-1280, 2008.

[15] A. Lazarus, B. Prabel, and D. Combescure, "A 3D finite element model for the vibration analysis of asymmetric rotating machines," Journal of Sound and Vibration, vol. 329, no. 18, pp. 3780-3797, 2010.

[16] M. W. Meng, W. J. Jun, and W. Zhi, "Frequency and stability analysis method of asymmetric anisotropic rotor-bearing system based on three-dimensional solid finite element method," Journal of Engineering for Gas Turbines and Power, vol. 137, no. 10, p. 102502, 2015.

[17] H. Taplak and M. Parlak, "Evaluation of gas turbine rotor dynamic analysis using the finite element method," Measurement, vol. 45, no. 5, pp. 1089-1097, 2012.

[18] M. H. Jalali, M. Ghayour, S. Ziaei-Rad, and B. Shahriari, "Dynamic analysis of a high speed rotor-bearing system," Measurement: Journal of the International Measurement Confederation, vol. 53, pp. 1-9, 2014.

[19] W. J. Chen, "Rotordynamics and bearing design of turbochargers," Mechanical Systems and Signal Processing, vol. 29, pp. 77-89, 2012.

[20] S. M. Jeon, H. D. Kwak, S. H. Yoon, and J. Kim, "Rotordynamic analysis of a high thrust liquid rocket engine fuel (Kerosene) turbopump," Aerospace Science and Technology, vol. 26, no. 1, pp. 169-175, 2013.

[21] B. Bai, L. Zhang, T. Guo, and C. Liu, "Analysis of dynamic characteristics of the main shaft system in a hydro-turbine based on ANSYS," in Proceedings of the 1st International Conference on Advances in Computational Modeling and Simulation (ACMS '11), pp. 654-658, December 2011.

[22] C.-N. Hsu, H.-W. D. Chiang, Y.-M. Huang, Y.-C. Fu, K.-H. Hsu, and C.-H. Li, "Rotor dynamics analysis and testing of a turbomolecular pump rotor-bearing system," in Proceedings of the ASME Turbo Expo: Turbine Technical Conference and Exposition (GT '11), pp. 409-416, June 2011.

[23] K. Ryu and A. Cavagnaro, "Predictions of rotordynamic performance for electric turbocompound," in Proceedings of the ASME Turbo Expo 2012: Turbine Technical Conference and Exposition (GT 2'12), pp. 743-751, Copenhagen, Denmark, June 2012.

[24] D.-K. Hong, B.-C. Woo, and D.-H. Koo, "Rotordynamics of 120 $000 \mathrm{r} / \mathrm{min} 15 \mathrm{~kW}$ ultra high speed motor," IEEE Transactions on Magnetics, vol. 45, no. 6, pp. 2831-2834, 2009.

[25] S. Nagesh, A. M. Junaid Basha, and T. D. Singh, "Dynamic performance analysis of high speed flexible coupling of gas turbine engine transmission system," Journal of Mechanical Science and Technology, vol. 29, no. 1, pp. 173-179, 2015.

[26] B. S. Choe, T. H. Kim, C. H. Kim, and Y. B. Lee, "Rotordynamic behavior of $225 \mathrm{~kW}$ (300 HP) class PMS motor-generator system supported by gas foil bearings," Journal of Engineering for Gas Turbines and Power, vol. 137, no. 9, Article ID 092505, 2015.

[27] J. D. Jovanovi and R. N. Tomovi, "Analysis of dynamic behaviour of rotor-bearing system," Proceedings of the Institution of Mechanical Engineers, Part C: Journal of Mechanical Engineering Science, vol. 228, no. 12, pp. 2141-2161, 2014.

[28] R. U. Mendes, K. L. Cavalca, and L. O. S. Ferreira, "Analysis of a complete model of rotating machinery excited by magnetic actuator system," Proceedings of the Institution of Mechanical Engineers, Part C: Journal of Mechanical Engineering Science, vol. 227, no. 1, pp. 48-64, 2013.

[29] D. Gayen and T. Roy, "Finite element based vibration analysis of functionally graded spinning shaft system," Proceedings of the Institution of Mechanical Engineers, Part C: Journal of Mechanical Engineering Science, vol. 228, no. 18, pp. 3306-3321, 2014.

[30] D. Biliotti, A. Bianchini, G. Vannini et al., "Analysis of the rotordynamic response of a centrifugal compressor subject to aerodynamic loads due to rotating stall," Journal of Turbomachinery, vol. 137, no. 2, Article ID 021002, 2015.

[31] F. Nonato and K. L. Cavalca, "An approach for including the stiffness and damping of elastohydrodynamic point contacts in deep groove ball bearing equilibrium models," Journal of Sound and Vibration, vol. 333, no. 25, pp. 6960-6978, 2014.

[32] J. Zapoměl and P. Ferfecki, "A computational investigation on the reducing lateral vibration of rotors with rolling-element bearings passing through critical speeds by means of tuning the stiffness of the system supports," Mechanism and Machine Theory, vol. 46, no. 5, pp. 707-724, 2011.

[33] H.-L. Zhou, G.-H. Luo, G. Chen, and F. Wang, "Analysis of the nonlinear dynamic response of a rotor supported on ball bearings with floating-ring squeeze film dampers," Mechanism and Machine Theory, vol. 59, pp. 65-77, 2013.

[34] X. Dai, Z. Shen, and H. Wei, "On the vibration of rotor-bearing system with squeeze film damper in an energy storage flywheel," International Journal of Mechanical Sciences, vol. 43, no. 11, pp. 2525-2540, 2001.

[35] J. A. Wensing, On the dynamics of ball bearings [Ph.D. thesis], 1998, http://purl.utwente.nl/publications/32063.

[36] Q. Tan and X. Li, "Analytical study on effect of a circumferential feeding groove on unbalance response of a flexible rotor in squeeze film damper," Tribology International, vol. 32, no. 10, pp. 559-566, 1999. 


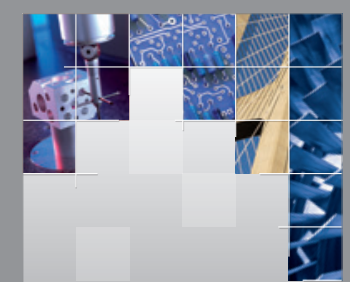

\section{Enfincering}
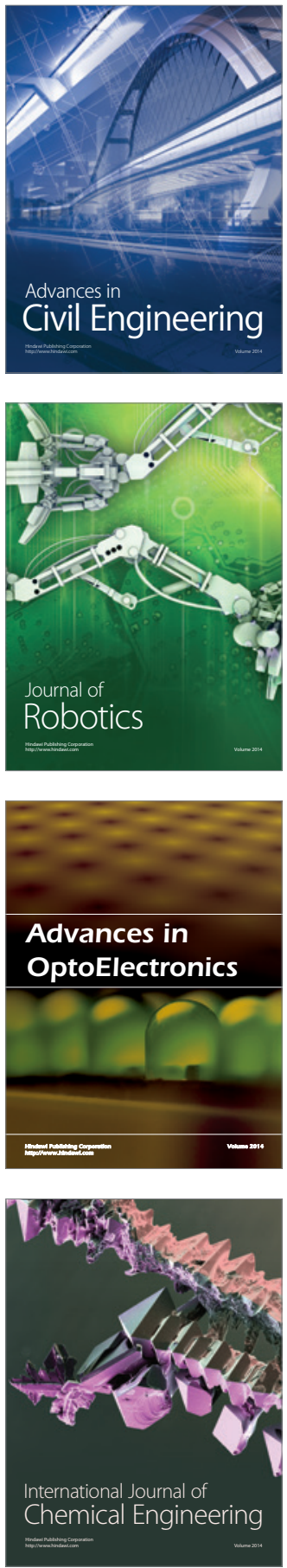

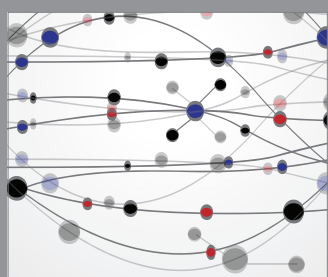

The Scientific World Journal

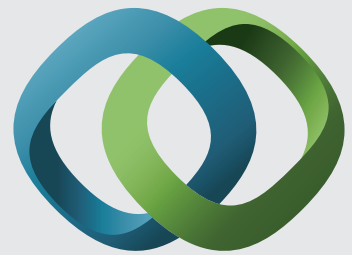

\section{Hindawi}

Submit your manuscripts at

https://www.hindawi.com
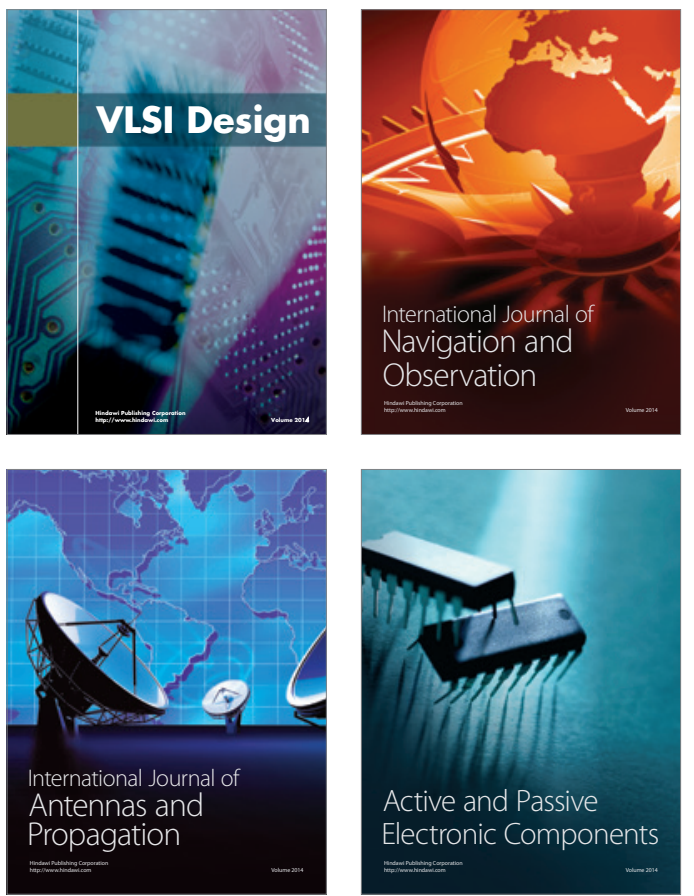
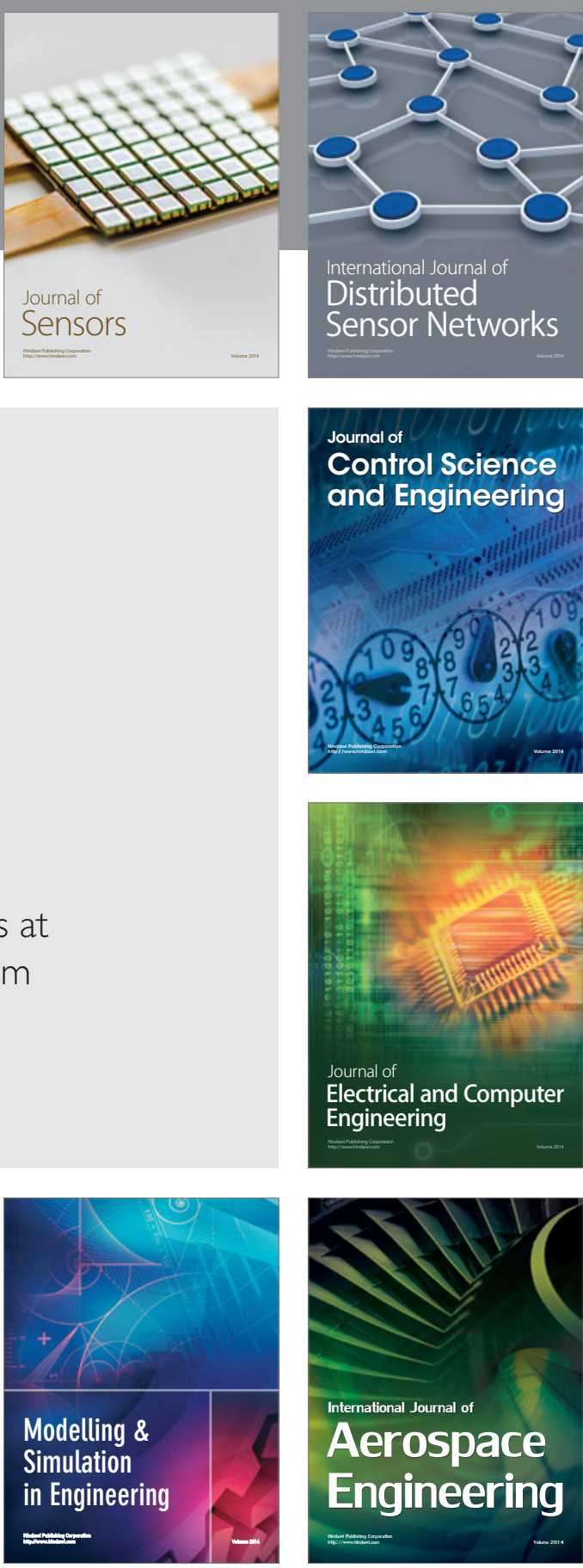

International Journal of

Distributed

Sensor Networks

$-$

Joumal of

Control Science

and Engineering
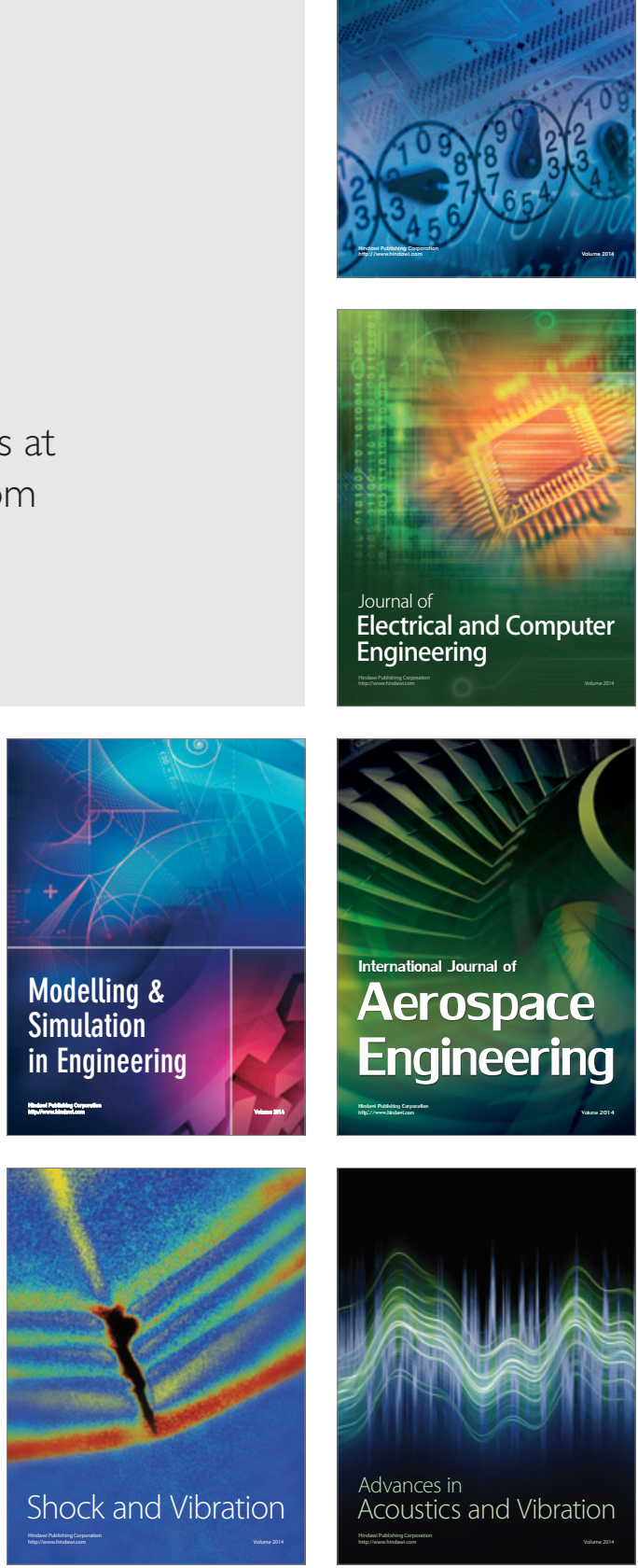